\title{
Service-learning Education Improvement for Foreign Language Learners
}

\author{
Mario Fabricio Ayala Pazmino \\ Universidad de Guayaquil, Ecuador
}

\begin{abstract}
The problem addressed in this study was the decreasing rate of enrolment in foreign language programs by Australian university students. A mixed-methods research methodology was used, with the quantitative data collected through tests conducted on participants and the qualitative data collected through semi-structured interviews. The sample consisted of 62 students enrolled in a Spanish foreign language program at a university in Melbourne. The student participants were divided into two groups: a control group, which had 31 students, and an experimental Service-Learning (SL) group, which also had 31 students. The students were also divided into two groups according to academic level: intermediate and advanced. Each group completed three academic tests: listening, oral and language use, reading and writing, both pre- and post-intervention. Findings were that oral language proficiency increased for students that had taken the SL program. They showed no significant increase in listening, reading, and writing. These effects did not differ significantly by level of academic achievement.
\end{abstract}

Index Terms - second language learning, service-learning, foreign language acquisition, Spanish language teaching, foreign language pedagogy

\section{INTRODUCTION}

There has been a decline in Australia among students enrolled in foreign language courses. In the 1960s, approximately $40 \%$ of Australian high school students were studying foreign languages (Munro, 2016). In 2016, this percentage had declined to $10 \%$ (Munro, 2016). This lack of interest has been described as a disadvantage for the country, as the decreasing number of students enrolled in these courses is despite the nation's schools having been allocated millions of dollars to promote foreign language learning (Munro, 2016). To improve students' interest in foreign language courses, this study focused on the incorporation of Service-Learning (SL) programs into the foreign language curriculum, particularly in Spanish-language courses at the tertiary school level.

$\mathrm{SL}$ is an educational experience based on a designed course in which students partake in service-based activities that correspond to the needs of the community and provide a broader understanding of the particular course subject, along with an increased sense of civic responsibility (Bringle \& Hatcher, 1995). SL has been described as a type of citizen education, highlighting its concern with social service (Carney, 2013). SL programs are concerned with the development of individuals and communities in which the participating individuals serve. According to Eyler and Giles (1999), the benefits of SL experiences include interpersonal and personal development, community relationships and leadership, application of learning and experience, ability to deal with social issues, reflection, curiosity, and engagement, curiosity regarding the problems faced by the community, problem-solving and critical thinking, and transformation of perspectives.

Recently, SL has been used to enrich foreign language courses around the world (Hartman \& Kiely, 2014; Keen \& Pease, 2016). Some SL programs related to foreign language courses may involve students in face-to-face contact with native speakers of the language, as interpersonal communication between native speakers and language learners has been found to yield higher academic scores in such courses (Hummel, 2013). As a result, SL has been found to build students' language skills, in addition to assisting with critical thinking, which enhances the students' ability to relate to other people by crossing social hurdles (Keen \& Pease, 2016; Hebert \& Hauf, 2015). Although the benefits of SL learning in foreign language courses have been studied previously (Eyler \& Giles, 1999; Hullender et al., 2015; Keen \& Pease, 2016; Kilgo, 2014; Murray, 2010), there is a lack of research about SL in the context of foreign language acquisition in Australia.

Existing studies mainly focus on SL participants' attitudes toward their SL experience and toward the Spanish language and culture, specifically (Beebe \& DeCosta, 1993; Abbott \& Lear, 2010; Morris, 2001; Mullaney, 2005; Overfield, 1997; Polansky, 2004; Varas, 2005; Varona, 2005; Weldon \& Trautmann, 2003). Fewer researchers, however, have examined the academic achievement of language learners in the context of their SL experience. There is a need to examine the influence of SL in encouraging foreign language learning, given the low rate of enrolment in language courses.

As stated, this study focuses on the application of SL as a learning intervention in foreign language acquisition in Australia. The general problem under study is the lack of enrolment in foreign language programs among Australian university students. In response to this problem, the goals of this study are: 
- To determine how SL affects the language acquisition of Spanish-language students and if so, how that impact occurs.

- To explore the perceptions and experiences of Spanish-language students who take part in a non-profit SL program.

- To examine how perceptions of SL compare to students' perceptions of traditional approaches to language acquisition.

The following research questions and subquestion will guide this study:

RQ1: How does SL affect the Spanish language acquisition of students enrolled in a Spanish foreign language program?

RQ2: What are the perceptions and experiences of Spanish language students who take part in a non-profit SL program?

RQ 2.1: How do Spanish language students' perceptions of SL compare to their perceptions of traditional approaches to language acquisition?

To conduct this study, a mixed-methods research methodology was selected, with the quantitative data collected through language skills tests conducted with participants and the qualitative data collected through semi-structured interviews. The quantitative data will be used to determine how participants' language acquisition was affected by SL, while the qualitative data will provide insight into participants' perceptions and experiences with SL and other language acquisition approaches. The SL model underpins this study, which is a type of experiential learning that is consistent with the experiential learning theory (Butler, 2013). The SL model is comprised of five steps that participants experience as part of their community service involvement (Zapata, 2011). These five steps include: 1) exploration, 2) clarification, 3) realization, 4) activation, and 5) internalization. The participants' progression through these steps is formed by the extent of their involvement, their outcomes and needs, the time, and the balance between support and challenges that are provided by the experience (Zapata, 2011).

The findings of this research will be significant for Australian students, primarily as a teaching intervention. This information will also be useful for education policy-makers in Australia, should they consider including SL as a part of the curriculum in the secondary school system, as that is where most students acquire second language skills.

\section{Background}

Historically, the use of SL in the field of education is a recent development, having been first explored as pedagogy in the 1990s (Kilgo, 2014). Educators working on SL noted the effectiveness of utilising experiences outside of the classroom to help students construct meaning out of abstract concepts and theories (Cress et al., 2012). SL is not an additional program for the community, but rather, a self-contained educational experience that is intimately associated with the course content (Hartman \& Kiely, 2014). This is because SL predominately takes place in an academic setting. For this reason, one of the most significant advantages of SL that differentiates it from other service experiences is its intimate association with a formal course (Murray, 2010). As a part of the formal education experience, SL allows a student to gain complete knowledge of the course material in a practical context (Mitchell, 2014). Due to the structured time of the course, SL allows the student to think about the lessons even after the course is completed, mostly in the form of other activities that may be used to express learning (Hartman \& Kiely, 2014).

As stated previously, the SL model is comprised of five steps, which include: 1) exploration, 2) clarification, 3) realisation, 4) activation, and 5) internalisation. Exploration refers to the students' excitement at the beginning of the SL classroom course. Clarification is the process of becoming informed about the real nature of the experience and its importance. Realisation refers to the understanding that occurs through clarification on the meaning of SL. Activation refers to the participation phase. Finally, internalisation is the phase in which the experience gained through the SL influences the student's decisions in life, especially in a vocational context. The claim is that these phases need to be successfully realised along with the quality and content of the students' experience in the course (Zapata, 2011). Eyler and Giles (1999) documented the benefits that resulted from the role of SL in studying a foreign language. These factors included interpersonal and personal development, such as deeper integration within the community, leadership, collaboration, and diversity learning; application and understanding of knowledge, such as use of experience and subject matter, understanding of diverse social problems and the will to do hard work; reflection, curiosity, and engagement, such as the ability to associate personal experience with learning, increased curiosity regarding the problems faced by the community; problem-solving and critical thinking; transformation of perspective, such as fresh perspectives on social justice and social problems; and citizenship, such as higher community participation through the development of commitment, skills, knowledge, and values.

Research suggests that SL programs can help students become better learners through regular continuous reflection, problem-solving, metacognition, and gathering of information (Kilgo, 2014). SL can positively influence students' application and understanding of concepts and materials from a course by connecting textbook knowledge to relevant experiences that students actively participate in (Keen \& Pease, 2016). Many students studying language who finished international SL programs have reported a significant increase in their motivation to learn the language studied (Barreneche \& Ramos-Flores, 2013). It has also been found that those who study language acquisition along with SL are more self-confident when talking with the population that natively speaks language under study (Hummel, 2013). When students communicate with others that differ culturally and/or linguistically from them during SL programs, the 
students are forced to develop unique mechanisms to address new and unfamiliar situations. SL provides exposure to cultural beliefs and values, which fosters the language acquisition process (Fair \& Delaplane, 2014).

The benefits of SL for foreign language acquisition include enrichment of students' motivation and confidence to use the foreign language studied, development of sensitivity and empathy for other cultures, decrease in stereotyping, enhanced sense of closeness and solidarity with the community, greater awareness of political and social problems, and a strong incentive to communicate in other languages outside of the school environment (Buff et al., 2014; Hartman \& Kiely, 2014; Keen \& Pease, 2016; Pierrakos et al., 2014). Despite evidence of the efficacy of the SL approach as an intervention strategy within foreign language programs in many countries, there remains a significant lack of research on SL in the context of foreign language acquisition in Australia (Hartman \& Kiely, 2014; Keen \& Pease, 2016). Researching application of SL within foreign language programs in Australia may help to determine whether the SL approach is a viable strategy for addressing the lack of enrolment in foreign language programs among Australian university students.

\section{MEthodology}

The purpose of this study was to examine the importance of SL in foreign language acquisition as a teaching methodology. This study employed both quantitative and qualitative methodologies. The data consisted of language skills tests given to the sample of students both before and after a SL program was administered and semi-structured interviews of those students.

The population included tertiary students enrolled in the Spanish foreign language program at a university in Melbourne, Australia. The sample consisted of 62 students, which were divided into two groups: the control group, which had 31 students, and the experimental group, which also had 31 students. The students were randomly assigned to a group through a computer program. Among these students, 38 were enrolled at the intermediate level (19 students in the experimental group, 19 students in the control group), and the remaining 24 were part of the advanced level course (12 students in each group). The sample included participants between the ages of 18 and 29, with a mean age of 22.39. Among the total participants, $87 \%$ (54 respondents) were Australian. The sample was roughly equal in gender, but that demographic factor was not recorded or considered in the data analysis.

Students from the two levels (intermediate and advanced) and both groups (control and experimental) were assessed regarding aspects of their Spanish language skills. A series of tests were carried out in agreement with the Spanish Department of the local university. Tests were divided into two phases: pre-SL and post-SL. The pre-tests were applied as follows: the students took a 2.5 -hour pre-test on language use, reading and writing, followed by a 25 -minute pre-test on listening and an oral test, which lasted approximately five minutes per person.

The researcher planned the service component with the students from the experimental group. This involved members from the Community Partner, a non-profit that serves the welfare of migrants, expatriates and international students from Latin America. Some 100 Latin Americans volunteered to participate in the program. Before the initiation, the needs of each student were analysed to create individualised programs of learning. Due to the high number of Latin American participants, each student from the experimental group was paired with two or more Latin Americans. To expose the participants to different accents and personalities, the groups changed every week.

Within the program, the hours spent in student-speaker interaction were grouped depending on the activity undertaken. This included (a) joint mentoring hours, wherein a dual activity was performed with the researcher; (b) hours of individual tutorial, which were weekly sessions; (c) hours of group work, which served to prepare for direct meetings; (d) hours to get to know the community partner, which was the time spent learning about how to develop the service; (e) hours of direct service, which were the sessions with the Latin American participants; (f) hours of group reflection, where the experimental group experience was discussed; and (g) hours of testing and evaluation. As a conclusion to the data on the duration and intensity of the program, 74 hours of work were invested during the seven weeks of the program. This represented an average of 10.6 hours per week and every day, with each person devoting 1.5 hours to the project each day. To maintain a position of equality, the control group researched topics related to the subject, which was equated to the investment of hours by the experimental group, although this calculation was approximate.

Within the final phase, two types of evaluation were done. This included the investigation of qualitative and quantitative aspects, as well as a program assessment. In the same way it was performed at the start of the program, all students (control and experimental) took the post-tests that were applied in the following manner: first, the students took the 2.5-hour post-test in language use, reading and writing, followed by a 25-minute post-test of listening, and an oral test, which lasted for approximately five minutes per person. A structured interview with each student in the experimental group was also conducted, which lasted some 45 minutes. Until the interviews, students were unaware of their test scores. This interview was divided into four sections, which included: personal information and previous experiences in similar projects; the motives and objectives behind their participation; their impressions and knowledge before their involvement in the program; and their experiences and the impact and benefits that, in their opinion, they achieved from the program. The students, the researcher and the representatives of the Community Partner jointly evaluated the program. 


\section{RESULTS}

Both qualitative and quantitative analysis methods were used during this research. These approaches were used to comprehensively address each research question and sub-question; quantitative analysis informed findings concerning the first research question, while qualitative analysis informed findings regarding the second research question and subquestion. The following sections will detail both analysis approaches.

Quantitative analysis. The quantitative analysis portion of the study assessed the means, standard deviations and estimates of reliability to provide evidence for the robustness of each of the test score totals, including the listening test, the oral test and the language use, reading and writing tests, pre- and post-test. These total scores were then used in a repeated measure multivariate analysis of variance (MANOVA) to evaluate the differences between the experimental and control groups over time.

TABLE I

MEANS, STANDARD DEVIATIONS AND ESTIMATES OF RELIABILITY

\begin{tabular}{|c|c|c|c|c|c|c|c|c|}
\hline & \multicolumn{4}{|c|}{ Intermediate with SL } & \multicolumn{4}{|c|}{ Intermediate without SL } \\
\hline & $\mathrm{N}$ & Mean & SD & alpha & $\mathrm{N}$ & Mean & SD & alpha \\
\hline Listening Test 1 & 19 & 69.88 & 10.19 & 0.82 & 19 & 67.03 & 7.80 & 0.96 \\
\hline Listening Test 2 & 19 & 75.27 & 9.24 & 0.97 & 19 & 70.82 & 8.51 & 0.97 \\
\hline Oral Test 1 & 19 & 75.39 & 14.51 & 0.91 & 19 & 72.19 & 12.47 & 0.97 \\
\hline Oral Test 2 & 19 & 79.03 & 15.95 & 0.99 & 19 & 75.63 & 13.56 & 0.98 \\
\hline $\begin{array}{l}\text { Language Use, Reading, and } \\
\text { Writing Test } 1\end{array}$ & 19 & 70.07 & 13.54 & 0.93 & 19 & 67.84 & 13.70 & 0.91 \\
\hline $\begin{array}{l}\text { Language Use, Reading, and } \\
\text { Writing Test } 2\end{array}$ & 19 & 75.95 & 13.84 & 0.94 & 19 & 71.74 & 15.55 & 0.94 \\
\hline & \multicolumn{4}{|c|}{ Advanced with SL } & \multicolumn{4}{|c|}{ Advanced without SL } \\
\hline & $\mathrm{N}$ & Mean & SD & alpha & $\mathrm{N}$ & Mean & SD & alpha \\
\hline Listening Test 1 & 12 & 64.91 & 8.89 & 0.97 & 12 & 59.08 & 17.06 & 0.99 \\
\hline Listening Test 2 & 12 & 73.08 & 9.46 & 0.96 & 12 & 62.67 & 17.50 & 0.99 \\
\hline Oral Test 1 & 12 & 67.50 & 12.03 & 0.84 & 12 & 71.50 & 18.72 & 0.86 \\
\hline Oral Test 2 & 12 & 75.83 & 11.17 & 0.77 & 12 & 72.92 & 17.03 & 0.89 \\
\hline $\begin{array}{l}\text { Language Use, Reading, and } \\
\text { Writing Test } 1\end{array}$ & 12 & 60.48 & 9.92 & 0.88 & 12 & 62.03 & 16.40 & 0.88 \\
\hline $\begin{array}{l}\text { Language Use, Reading, and } \\
\text { Writing Test } 2\end{array}$ & 12 & 66.24 & 9.82 & 0.87 & 12 & 65.93 & 14.34 & 0.91 \\
\hline
\end{tabular}

The means, standard deviations and effect sizes for the oral tests show that there were increases in the oral for the advanced experimental group compared to the control group, but for the intermediate, both the experimental and control groups increased from Time 1 to 2 similarly. Thus, the most significant effect of the SL program was that oral language skills increased the most for advanced students, although the SL students generally outperformed the control group at the end of the program. The graph (Figure 1) shows more clearly the increase for the experimental group compared with the control group, suggesting that their higher levels of Spanish proficiency possibly assisted with their growth in oral language. On listening and oral, the experimental group proficiency increased more than that of the control group. The same pattern could be seen for language, but it was not quite statistically significant. 


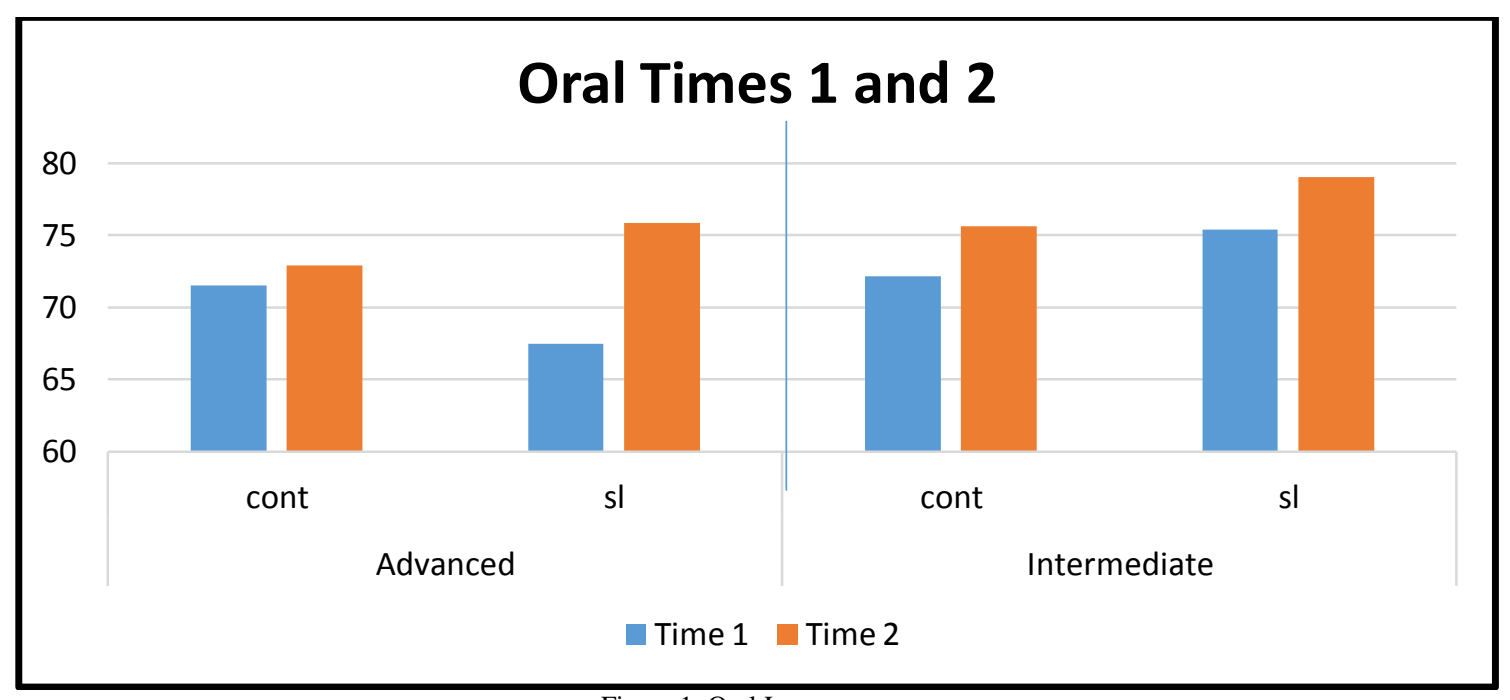

Figure 1. Oral Language

Specifically, the pre- and post-analyses showed that there was the highest increase in oral proficiency from participating in the SL for the advanced group $(\mathrm{d}=.78)$ compared to the control $(\mathrm{d}=.08)$, but for the intermediate students in both the experimental and control groups, oral proficiency also increased similarly, from Time 1 to Time 2 $(\mathrm{d}=.26, .23)$. In the case of listening tests, SL students performed higher relating to listening (.68 versus .29) and oral (.39 versus .18), but not language, for both advanced and intermediate combined. Furthermore, there were no effects identified from the analysis of language use, reading and writing in any comparison.

More limitations, extraneous variables, and alternative explanations were revealed for the quantitative results than the qualitative results. For instance, though oral proficiency increased significantly for advanced students in the SL group in comparison to the control, the high standard deviation coefficients considered in relation to the small number of student participants considered $(n=12)$ demonstrates that scores varied significantly among participants in all experimental groups; while the advanced SL group's oral proficiency increased significantly when considering shifts in scores on average, examination of individual score changes between the first and second oral tests reveals that two participants' scores increased by as few as three points, while three participants' scores increased by twelve or more points. Thus, the influence of extraneous variables, such as students' gender, cultural background, and GPA should be considered to explain differences in score increases between the first and second tests. Additionally, because the control group did not participate in the interview portion of the research, qualitative insights concerning differences in participants' perceptions and experiences could not contextualize the quantitative differences evident in participants' test scores.

Qualitative analysis. Analysis of the qualitative (interview) data showed that most of the students preferred the mix of both traditional pedagogy (non-service learning) and SL methods. Their main reason for choosing the combination method was that the traditional approach was better for the theory classes and the SL technique was suitable for practice sessions and for making conversation. In addition, "achieving more confidence and security in Spanish" was the primary learning goal of the students participating in the SL program. Furthermore, 30 out of the 31 students in the experimental group $(96.77 \%)$ perceived that the program was useful in meeting their learning goals of the Spanish course. The majority of students $(96.77 \%)$ indicated that their participation in the SL project helped increase their motivation to learn Spanish. After completion of the SL program, most of the participants felt confident regarding their judgment of the culture, as well as identity. During the qualitative analysis, it was noted that 12 of the respondents $(38.71 \%)$ said their work in community service had an academic impact, and 15 of the respondents (48.39\%) asserted that their participation had an impact of social nature. It was noted that 29 of the respondents (93.55\%) were positive about joining a similar SL program in the future. When the respondents were asked to describe the connection between the SL program and the real world, $93.55 \%$ claimed that the program helped them connect what they learned in the classroom to reality. There were also several suggestions received about improvements that could be made in the future SL program, such as adjusting program times, having fewer participants, including different stimulants to improve the conversation between the groups, and incorporating a more structured approach to gain more from the program. While these results generally reflect the positive effects, SL had on participants' academic and social experiences, it should be reiterated that only participants in the experimental group provided interview data. Thus, despite the SL groups producing significantly better test outcomes on several measures, it is possible that interviewing the control group would have revealed similar improvements for variables such as student motivation and social skills.

The second section of the qualitative analysis assessed the reactions from those in the SL program. Most of the respondents said that it was awkward at the beginning, but that everybody eased into it as he or she developed a sense of comfort and trust with one other. When consulted about how the reactions from the Latin Americans shaped their participation, the students asserted their response made them more comfortable in helping the Latin Americans with their English skills. 
The third segment determined the difficulties that were faced by the respondents during the SL program. Most of the respondents agreed that they would not have been able to learn as much in the classroom as they have been during the SL program. Apart from this, 30 respondents $(96.77 \%)$ agreed that they would like to have such a program in their language course at the university. When the respondents were asked about their preference for the location of SL programs, 15 respondents $(48.39 \%)$ expressed an inclination for their university campus as a place for the development of SL program activities; 9 respondents $(29.03 \%)$ indicated their preference for a site closer to their university.

In the fourth segment, the researcher identified the benefits for the Spanish speakers from the SL program. It was noted that it was possible for the Latin Americans to improve their English-speaking skills as half of the interactions that took place were in English. This program also provided the Latin Americans with the opportunity to enhance their language proficiency to develop a better understanding of Australians and their culture. A total of $94 \%$ (29 respondents) of the participants responded positively when asked if the Latin Americans had enjoyed the SL program.

The fifth and final segment explained the relationship between the marks that were obtained by the participants during the quantitative tests and their self-assessment of their performance. When the respondents were solicited to selfassess their fulfilment in the SL program, most expressed satisfaction. However, there was no significant statistical relationship between the marks from the quantitative tests and their self-assessment of their achievement in the SL program. The program produced perceived benefits for the participants, but those benefits were not reflected in their test scores.

\section{DISCUSSION}

In this study, SL was defined as an educational experience based on a designed course in which students partook in service-based activities that correspond to the needs of the community. The SL program aimed to provide a more comprehensive understanding of the course subject along with an increased sense of civic responsibility (Bringle \& Hatcher, 1995). The literature suggested several benefits of SL for foreign language acquisition. These benefits that were also suggested in the qualitative phase of this study were fulfilment for students, motivation and confidence in using the foreign language studied, development of sensitivity and empathy for other cultures, decrease in stereotypes, enhanced sense of closeness and solidarity with community in general, higher awareness of political and social problems, and a strong motivation to communicate in other languages. The findings of this study corroborated the literature in this regard.

SL has been defined in several ways, and the goal of many of the researchers studying SL was to establish the credibility of SL in the context of education and show how SL programs could improve classroom education. This research study is part of this tradition; although the quantitative results regarding the use of SL in foreign language acquisition were mixed, both quantitative and qualitative results highlighted certain positive aspects of SL in the context of education, specifically foreign language acquisition.

For the first research question concerning how SL affects the Spanish language acquisition of the participating students, the results were mixed. Specific areas of proficiency were enhanced, such as listening and oral skills, while others were not. However, the quantitative analysis showed no effects on language use, reading, and writing tests from participation in the SL program among the student participants in any comparison. The results of this study did not indicate that SL was beneficial to the student participants' learning in and of itself. Rather, the SL activities consisted of direct interactions with native Spanish speakers, and those interactions boosted the participants' listening and oral language skills. This result might have been expected, as contact and interaction with native speakers is one of the most effective ways to acquire conversational skills in a foreign language. Thus, these findings suggest that SL may not improve academic performance directly as reflected by test scores and marks on formal reading, language, and writing tasks; rather, incorporating SL into foreign language programs may improve certain skills that contribute to academic outcomes indirectly, such as student motivation, confidence, and cultural awareness.

For the second research question and sub-question concerning the participating students' perceptions and experiences with the SL program, most of the participants from the experimental group developed friendships with the Latin Americans due to the positive attitudes of the latter, which made the program more comfortable for the SL group, motivated them, and made them feel useful. Additionally, the relationship between the real-world interactions as part of the SL program and the classroom curricular content resulted in better outcomes insofar as language skills and comfort in oral communication were concerned, as the results showed positive experiences of students with the program and its impact on the practical part of their learning. The results also suggested that facing unfamiliar conditions led the students to make an effort to be understandable. The SL experience resulted in the development of increased selfconfidence reported by the students. Despite these positive results, about half $(45.16 \%, 14$ participants) of the participants stated that they had difficulties with the time and the place where the program was developed.

\section{CONCLUSION}

There remains a need to understand if SL is particularly valuable in imparting foreign language skills. The best comparison for a follow-up study would be to compare SL to other forms of similar interaction. In this study, the SL was primarily conversational. Therefore, the most valuable comparison would be with other conversational interactions 
that are not SL in nature. In that way, researchers could determine if it was the fact that the students engaged in SL or the fact that they engaged in conversational activities that improved their oral and listening skills.

The results of this study reflect how innovative learning approaches, such as SL, may be applied in an effort to address the lack of enrolment in foreign language programs at Australian universities. While quantitative analysis alone did not suggest that incorporating SL will drastically improve formal testing and assignment outcomes, qualitative analysis of participants' interview responses revealed that the SL experience significantly improved many factors which contribute to academic outcomes. Confirmation of the extant research finding that SL can improve students' motivation to learn a foreign language is particularly notable given the enrolment problem at the core of the study.

The emphasis on SL in a language learning context should be promoted as it has a greater effect on experiential learning than on cognitive learning - at least, directly. The qualitative findings of this study, however, also suggest that experiential learning can lead to improved cognitive learning - in the case of language skills acquisition, the two cannot be separated. One can learn vocabulary and grammar from a textbook or by conversing with others. The signal finding of this study is that in a SL context, experiential learning is the dominant outcome, as opposed to cognitive learning.

\section{REFERENCES}

[1] Abbott, A., \& Lear, D. (2010). The connections goal area in Spanish Community Service-Learning: Possibilities and limitations. Foreign Language Annals, 43(2), 231-245.

[2] Barreneche, G. I. (2011). Project MUSE - language learners as teachers: Integrating service-learning and the advanced language course. Hispania, 94(1), 103-120. Retrieved from https://muse.jhu.edu/article/424432/summary (accessed 9/5/2019).

[3] Barreneche, G. I., \& Ramos-Flores, H. (2013). Integrated or isolated experiences? Considering the role of service-learning in the Spanish language curriculum. Hispania, 96(2), 215-228. doi:10.1353/hpn.2013.0063.

[4] Beebe, R., \& DeCosta, E. (1993). Teaching beyond the classroom - The Santa Clara University Eastside project community service and the Spanish classroom. Hispania, 76, 884-891.

[5] Bouvet, E., Cosmini, D., Palaktsoglou, M., \& Vanzo, L. (2017). 'Doing good' in Italian through student community engagement. Australian Review of Applied Linguistics, 40(2), 159-175.

[6] Bringle, R., \& Hatcher, J. (1995). A service learning curriculum for faculty. Michigan Journal of Community Service Learning, 2, 112-122.

[7] Bringle, R., \& Hatcher, J. (1999). Reflection in Service Learning: Making Meaning or Experience. Educational Horizons, 77(4), 179-185.

[8] Bruening, J. E., Peachey, J. W., Evanovich, J. M., Fuller, R. D., Murty, C. J. C., Percy, V. E., Chung, M. (2015). Managing sport for social change: The effects of intentional design and structure in a sport-based service learning initiative. Sport Management Review, 18(1), 69-85. doi:10.1016/j.smr.2014.07.002.

[9] Buff, S. M., Jenkins, K., Kern, D., Worrall, C., Howell, D., Martin, K., Blue, A. (2014). Interprofessional service-learning in a community setting: Findings from a pilot study. Journal of Interprofessional Care, 29(2), $159-161$. doi:10.3109/13561820.2014.934956.

[10] Butler, M. (2013). Learning from service-learning. PRIMUS, 23(10), 881-892. doi:10.1080/10511970.2013.775978.

[11] Cai, S., \& Zhu, W. (2012). The Impact of an Online Learning Community Project on University Chinese as a Foreign Language Students' Motivation. Foreign Language Annals, 45(3), 307-329. doi:10.1111/j.1944-9720.2012.01204.x.

[12] Carney, T. M. (2013). How service-learning in Spanish speaks to the crisis in the humanities. Hispania, 96(2), $229-237$. doi:10.1353/hpn.2013.0035.

[13] Crabtree, R. D. (2013). The intended and unintended consequences of international service-learning. Journal of Higher Education Outreach and Engagement, 17(2). Retrieved from http://works.bepress.com/robbin_crabtree/14/ (accessed 9/5/2019).

[14] Eyler, J. \& Giles Jr., D. E. (1999). Where's the Learning in Service-Learning? Jossey-Bass Higher and Adult Education Series. San Francisco, CA: Jossey-Bass, Inc.

[15] Fair, C. D., \& Delaplane, E. (2014). "It is good to spend time with older adults. You can teach them, they can teach You": Second grade students reflect on intergenerational service learning. Early Childhood Education Journal, 43(1), 19-26. doi:10.1007/s10643-014-0634-9.

[16] Goff, J. E. (2014). Impacts of service learning on undergraduate teaching assistants in an after-school program: A qualitative approach to discovery. Illuminare: A Student Journal in Recreation, Parks, and Tourism Studies, 12(1). Retrieved from https://scholarworks.iu.edu/journals/index.php/illuminare/article/view/4364 (accessed 9/5/2019).

[17] Goldfus, C. (2012). The challenges facing the foreign language teacher educator: A proposed teacher education model for EFL. Journal of NELTA, 16(1-2). doi:10.3126/nelta.v16i1-2.6125.

[18] Harrison, B., Clayton, P. H., \& Tilley-Lubbs, G. A. (2015). Troublesome knowledge, troubling experience: An inquiry into faculty learning in service-learning. Michigan Journal of Community Service Learning, 20(2). Retrieved from http://hdl.handle.net/2027/spo.3239521.0020.201 (accessed 9/5/2019).

[19] Hartman, E., \& Kiely, R. (2014). Pushing boundaries: Introduction to the global service-learning special section. Michigan Journal of Community Service Learning, 21(1), 55-63. Retrieved from https://eric.ed.gov/?id=EJ1116547 (accessed 9/5/2019).

[20] Hebert, A., \& Hauf, P. (2015). Student learning through service learning: Effects on academic development, civic responsibility, interpersonal skills and practical skills. Active Learning in Higher Education, 16(1), 37-49. doi:10.1177/1469787415573357.

[21] Hertzler, M. (2012). Service learning as a pedagogical tool for language teachers. In T. Sildus (Ed.), Touch the world: 2012 report of the Central States Conference on the Teaching of Foreign Languages (pp. 21-46). Eau Claire: RMT.

[22] Hullender, R., Michigan, C., Hinck, S., Wood-Nartker, J., Burton, T., \& Bowlby, S. (2015). Evidences of Transformative learning in service-learning reflections. Journal of the Scholarship of Teaching and Learning, 15(4), 58-82. Retrieved from http://josotl.indiana.edu/article/view/13432 (accessed 9/5/2019). 
[23] Hummel, K. M. (2013). Target-language community involvement: Second-Language linguistic self-confidence and other perceived benefits. Canadian Modern Language Review, 69(1), 65-90. doi:10.3138/cmlr.1152.

[24] Karaman, A. C. (2013). Community service learning and the emergence of systems thinking: A teacher education project in an urban setting in turkey. Systemic Practice and Action Research, 27(5), 485-497. doi:10.1007/s11213-013-9309-5.

[25] Keen, C. H., \& Pease, H. (2016). The role of service-learning and mentoring in the early career develop. The Qualitative Report, 21(1), 117-126. Retrieved from http://nsuworks.nova.edu/tqr/vol21/iss 1/10/ (accessed 9/5/2019).

[26] Kilgo, C. A. (2014). The estimated effects of participation in service-learning on liberal arts outcomes. The International Journal of Research on Service-Learning and Community Engagement, 2(1). Retrieved from http://journals.sfu.ca/iarslce/index.php/journal/article/view/78 (accessed 9/5/2019).

[27] Mitchell, T. D. (2014). Using a critical service-learning approach to facilitate civic identity development. Theory Into Practice. doi:10.1080/00405841.2015.977657.

[28] Morris, F. (2001a). Enhancing motivation and promoting positive attitudes through community experience. In G. Bräuer (Ed.), Pedagogy of language learning in higher education: An introduction (pp. 47-60). Westport, CT: Ablex Publishing.

[29] Morris, F. (2001b). Serving the community and learning a foreign language: Evaluating a service - learning programme. Language, Culture and Curriculum, 14, pp. 244-255.

[30] Mullaney, J. (2005). Service-learning and language acquisition theory and practice. In J. Hellebrandt, \& L. Varona (Eds.), Construyendo Puentes (Building Bridges) - Concepts and Models for service-learning in Spanish (pp. 49-60). New York, New York: Stylus Publishing.

[31] Munro, K. (2016). Why students are turning away from learning foreign languages. The Sydney Morning Herald. Retrieved from http://www.smh.com.au/national/education/why-students-are-turning-away-from-learning-foreign-languages-20160610gpg6ek.html (accessed 9/5/2019).

[32] Murray, J. S. (2010). Moral courage in healthcare: Acting ethically even in the presence of risk. OJIN: The Online Journal of $\begin{array}{lllll}\text { Issues } & \text { in } & \text { Nursing, } & \text { Retrieved } & \text { from }\end{array}$ http://www.nursingworld.org/MainMenuCategories/ANAMarketplace/ANAPeriodicals/OJIN/TableofContents/Vol152010/No 3-Sept-2010/Moral-Courage-and-Risk.html (accessed15/5/2019).

[33] Murray, S. V., \& Laura, F. (2002). 'Ti posso offrire un caffe?' Implementing an out-of-class experience in a tertiary Italian programme. In Proceedings of the Innovations in Italian Teaching Workshop (pp. 26-39). Griffith University.

[34] Overfield, D. (1997). An approach to service in the foreign language classroom. Mosaic, 4(2), 11-13.

[35] Polansky, S. G. (2004). Tutoring for community outreach: A course model for language learning and bridge building between universities and public schools. Foreign Language Annals, 37(3), 367-373.

[36] Scott, K. E., \& Graham, J. A. (2015). Service-learning: Implications for empathy and community engagement in elementary school children. Journal of Experiential Education, 38(4), 354-372. doi:10.1177/1053825915592889.

[37] Toporek, R. L., \& Worthington, R. L. (2014). Integrating service learning and difficult dialogues Pedagogy to advance social justice training. The Counselling Psychologist, 42(7), 919-945. doi:10.1177/0011000014545090.

[38] Varas, P. (2005). Raising cultural awareness through service learning in Spanish culture and conversation: Tutoring in the migrant education program in Salem. In J. Hellebrandt, \& L. Varona (Eds.), Construyendo Puentes (Building Bridges) Concepts and models for service- learning in Spanish (pp. 123-136) New York, New York: Stylus Publishing.

[39] Varona, L. T. (2005). From instrumental to interactive to critical knowledge through service learning in Spanish. In J. Hellebrandt, \& L. Varona (Eds.), Construyendo Puentes (Building Bridges) - Concepts and models for service learning in Spanish (pp. 61-76). New York, New York: Stylus Publishing.

[40] Weldon, A., \& Trautmann, G. (2003). Spanish and service-learning: Pedagogy and praxis. Hispania, 86(3), 574-585.

[41] Zapata, G. (2011). The effects of community service learning projects on L2 learners' cultural understanding. Hispania, 94(1), 102-86. Retrieved from https://muse.jhu.edu/article/424431/summary (accessed 20/5/2019).

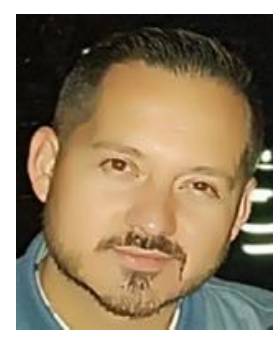

Mario Fabricio Ayala Pazmino, has degrees in Computer Science, Business Administration, Educational Sciences, and received his Ed.D. in 2018 from the University of Melbourne in Melbourne, Victoria, Australia, with his major concentration of study on languages other than English (LOTE), ESL and TESOL curriculum and pedagogy, and continuing and community education and higher education.

He currently works for De las Americas University (UDLA) in Quito, Ecuador as an educator and has past experience as an Academic Coordinator and Teaching Associate for Hispanic studies. His previous experience also includes working as a head of a Humanities Department, a head of a Community and Service Department, an examiner of Senior theses, and a Social Studies, ESL, and Technology teacher.

Dr. Ayala is a current member of the Monash University Teaching Association for Hispanic Studies. 